\title{
Development of Ti-15Zr-Mo alloys for applying as implantable biomedical devices
}

\author{
D.R.N. Correa ${ }^{\text {a, e, }{ }^{*} \text {, P.A.B. Kuroda }}{ }^{\text {b, e }}$, M.L. Lourenço $^{\text {b, e }}$, C.J.C. Fernandes ${ }^{\text {d }}$, M.A.R. Buzalaf ${ }^{\text {c }}$, \\ W.F. Zambuzzi ${ }^{\text {d, e, C.R. Grandini }}{ }^{\text {b, e }}$ \\ a IFSP - Federal Institute of Education, Science and Technology, 18095-410, Sorocaba, SP, Brazil \\ ${ }^{\mathrm{b}}$ UNESP - Univ Estadual Paulista, Laboratório de Anelasticidade e Biomateriais, 17.033-360, Bauru, SP, Brazil \\ ${ }^{c}$ USP - Universidade de São Paulo, Faculdade de Odontologia, Departamento de Ciências Biológicas, 17.012-901, Bauru, SP, Brazil \\ d UNESP - Univ Estadual Paulista, Departamento de Química e Bioquímica, 18618-970, Botucatu, SP, Brazil \\ ${ }^{\text {e } I B T N-B r}$ - Institute of Biomaterials, Tribocorrosion and Nanomedicine - Brazilian Branch, 17.033-360, Bauru, SP, Brazil
}

\section{A R T I C L E I N F O}

\section{Article history:}

Received 21 December 2017

Received in revised form

22 March 2018

Accepted 24 March 2018

Available online 27 March 2018

\section{Keywords:}

Titanium alloys

Microstructure

Mechanical properties

Biomaterial

\begin{abstract}
A B S T R A C T
In this study, the effect of molybdenum content in Ti-15Zr-based alloys (wt\%) was analyzed in terms of crystalline structure, microstructure, selected mechanical properties, and cytotoxicity. The samples were produced by argon arc-melting followed by hot rolling and heat treatment processes. The crystalline structure and microstructure were dependent of both alloying elements (zirconium and molybdenum). Ti-15Zr alloy displayed only laths of $\alpha^{\prime}$ phase, while the alloys up to Ti-15Zr-10Mo exhibited different proportions of $\alpha^{\prime}, \alpha$, and $\beta$ phases. Molybdenum content higher than $12.5 \mathrm{wt} \%$ fully stabilized the $\beta$ phase. Vickers microhardness values of Ti-15Zr-Mo alloys were higher than those of CP-Ti due to solid solution and phase precipitation strengthening. Young's modulus values of Ti-15Zr-Mo alloys were lower than those of CP-Ti due to $\beta$ phase stabilization. Cytotoxicity levels of Ti-15Zr-Mo alloys were within a tolerable range for biomedical purposes. In addition, we observed molybdenum content in Ti-15Zr-based alloys promoted an increase on pre-osteoblast adhesion up to $3 \mathrm{~h}$ of adhesion's time. Thus, Ti-15Zr-15Mo alloy presented better combination of properties than some traditional metallic biomaterials.
\end{abstract}

() 2018 Elsevier B.V. All rights reserved.

\section{Introduction}

Metallic materials are widely used in biomedical devices, especially in surgical instruments and orthopedic and dental implants [1]. One of the most widely used biomaterial is $316 \mathrm{~L}$ stainless steel, due its low cost and tolerable mechanical and electrochemical properties. Co-Cr-Mo alloys have also received attention from scientists due to their excellent corrosion and wear resistance [2]. However, concerns about mechanical compatibility and a lack of interaction between these materials and adjacent tissues have led to the use of alternative metallic materials for implants [3].

Titanium and its alloys have primarily been used since the midtwentieth century; this can be attributed to their many favorable properties, such as high specific strength, relatively low Young's modulus values, excellent corrosion resistance, and good

\footnotetext{
* Corresponding author. IFSP - Federal Institute of Education, Science and Technology, 18095-410, Sorocaba, SP, Brazil.

E-mail address: diego.correa@ifsp.edu.br (D.R.N. Correa).
}

biocompatibility [4,5]. Additionally, studies have demonstrated that Ti-based implants interact well with adjacent bone tissues, promoting an adequate osseointegration [5, 6]. Many of the Ti alloys developed for the aerospace industry began to be used as biomaterials, e.g. Ti-6Al-4V (Ti-64) alloy, which possesses an ideal combination of mechanical properties and corrosion resistance [2]. However, evidence of allergenic reactions and neurological problems linked to aluminum and vanadium ions required the processing of novel alloys, specifically designed for biomedical purposes [2, 7]. Since then, several alloys that possess adequate mechanical properties and provoke suitable biological responses within tissues and cells haven been produced, such as nitinol (equiatomic NiTi), Ti-13Nb-13Zr (Ti-1313), Ti-29Nb-13Ta-4.6Zr (TNTZ), Ti-12Mo-6Zr-2Fe (TMZF) and Ti-15Mo [8, 9].

New biomedical Ti alloys have been developed with a high concentration of $\beta$-stabilizer elements. The $\beta$ phase of titanium (body-centered cubic (bcc) crystalline structure) is an allotropic phase with lower elastic modulus compared to the $\alpha$ phase's (hexagonal close packed (hcp) crystalline structure) and the 
metastable phases ( $\alpha$ ' (distorted hcp), $\alpha$ " (orthorhombic) and $\omega$ (hcp ( trigonal)) [10,11]. Several $\beta$-type Ti alloys have been studied as potential solutions to the mismatch between the Young's modulus of the implant and the surrounding hard tissues, in order to avoid stress shielding effects. The most common alloying elements added to these new alloys have been niobium, tantalum, zirconium, and molybdenum, as they do not exhibit any cytotoxic reaction when in contact with cells [2,12]. Zirconium is in the same titanium's chemical group, being able to improve mechanical strength and biocompatibility in binary Ti-Zr alloys [13, 14]. Molybdenum is a strong $\beta$-stabilizer, which can decrease the Young's modulus and improve corrosion resistance in binary Ti-Mo alloys [15, 16].

Recent biomedical Ti alloy's design has been based on the electronic orbital method and electron/atom ratio approaches, which can result in multi-compositional alloys with tailored properties. Santos et al. [17] developed low-cost Ti-Mn-Mo alloys that presented low Young's modulus values and high mechanical strength. Abd-Elrhman et al. [18] designed a low-cost Ti-Mo-Fe alloy using an electronic approach, which exhibited improved mechanical properties and a better Young's modulus than Ti-6Al4V. Ozan et al. [19] studied Ti-Nb-Zr alloys in order to create materials with an adequate mechanical compatibility for short-term orthopedic implants. Mello et al. [20] investigated Ti-Mo-Sn alloys pursuing $\beta$-type implants with low Young's modulus values.

In this scenery, Ti-Mo and Ti-Zr based alloys have been the subject of intense research, which has highlighted their immense potential for use as biomaterials [21, 22]. By combining the effects of both alloying elements, Ti-Zr-Mo alloys have the potential to be interesting alternatives to this new class of biomedical Ti alloys. In our previous study in Ti-Zr alloys [23], we found that Ti-15Zr alloy presented distinct Vickers microhardness, Young's modulus, and cytotoxicity levels when compared to other contents of $\mathrm{Zr}$ and $\mathrm{CP}-$ Ti. Taking this into account, the present paper aims to analyze the phase composition, microstructure, selected mechanical properties (including microhardness and Young's modulus), cytotoxicity and pre-osteoblast adhesion performance of the Ti-15Zr alloy when different amounts of Mo were added. Addressed this issue, it was sought to identify the best combination of properties for biomedical applications.

\section{Materials and methods}

Ingots of Ti-15Zr-xMo $(x=0,2.5,5,7.5,10,12.5,15$, and $20 w t \%)$, with mass around $60 \mathrm{~g}$, were obtained by arc-melting from CP-Ti bars (grade 2 ), pure $\mathrm{Zr}$ sheets (99.8\%), and pure Mo wires (99.9\%). The metals were melted in a water-cooled copper crucible in an argon atmosphere. The ingots were melted five times to ensure acceptable homogeneity. Subsequently, the ingots were submitted to hot rolling at $1273 \mathrm{~K}$ followed by air-cooling. Finally, the samples were subjected to a recrystallization treatment in a vacuum of $10^{-5}$ Torr at $1273 \mathrm{~K}$ for $86.4 \mathrm{ks}$ and slowly cooled $(5 \mathrm{~K} / \mathrm{min})$.

Chemical composition and mapping were evaluated by energy dispersive spectroscopy (EDS; Oxford detector, Inca X-Act model). The alloying elements were quantified by an average of five distinct regions. Gas (oxygen and nitrogen) content was evaluated by LECO TC400 equipment. The density values were obtained from the Archimedes' principle using pure water. The experimental densities were compared to the theoretical values obtained from the weighted average densities of the alloying elements ( $\mathrm{Ti}, \mathrm{Zr}$ and $\mathrm{Mo}$ ).

The crystalline structure was evaluated with X-ray diffraction measurements (XRD; Rigaku D/Max 2100/PC diffractometer) obtained by powder method operating at $40 \mathrm{kV}$ and $20 \mathrm{~mA}$. The data were collected with monochromatic $\mathrm{Cu}-\mathrm{K}_{\alpha}$ radiation $(\lambda=1.544 \AA)$ between $10^{\circ}$ and $100^{\circ}$ with a step size of $0.02^{\circ}$ and a collection time of $3.2 \mathrm{~s}$. Phase composition analysis was conducted by Rietveld's method using standard crystallographic sheets and GSAS/EXPGUI software. Microstructural analysis was performed by optical microscopy (OM; BX51M Olympus microscope) and scanning electron microscopy (SEM; Carl Zeiss EVO LS15 equipment). Metallographic preparation was conducted by grinding the surface with SiC abrasive papers (down to 1500 grit), polishing with alumina and diamond colloidal suspensions, and etching with an acid solution of $\mathrm{H}_{2} \mathrm{O}, \mathrm{HNO}_{3}$, and $\mathrm{HF}(80: 15: 5)$.

Selected mechanical properties evaluation used Vickers microhardness and Young's modulus measurements following standard procedures [24, 25]. Vickers microhardness values were measured with a Shimadzu HMV-2 microdurometer with load of $0.200 \mathrm{kgf}$ $(1.961 \mathrm{~N})$ and dwell time of $60 \mathrm{~s}$. Young's modulus values were obtained at room temperature using the impulse excitation technique, based on the free resonance vibration, with Sonelastic ${ }^{\mathbb{B}}$ equipment from ATCP Physical Engineering. Average values were calculated from five measurements in each sample. Statistical analysis was carried out by ANOVA test $(p<0.01)$.

In vitro indirect cytotoxicity and adhesion assays were performed using MC3T3-E1 pre-osteoblast cells (subclone 4) following the protocols established by ISO 10993-5 [26]. The cells were cultured in 10\% Fetal Bovine Serum (FBS) and antibiotics (100 mg/ $\mathrm{mL}$ penicillin, $100 \mathrm{mg} / \mathrm{mL}$ streptomycin) at $37^{\circ} \mathrm{C}$ in a $5 \%$ carbon dioxide atmosphere. The samples were kept with the culture medium (without FBS, $0.2 \mathrm{mg} / \mathrm{mL}$ ) during $24 \mathrm{~h}$ for conditioning the medium (designated "conditioned medium"). Thereafter, conditioned medium was used to treat semi-confluent pre-osteoblast cells in order to evaluate its toxicity as proposed in MTT colorimetric protocol (3-[4.5-dimetiltiazol-2-yl]-2.5-diphenyl bromide). The cytotoxicity level was assayed by absorbance $(570 \mathrm{~nm})$ in a microplate reader (Biotek, USA). For the adhesion assay, the cells were treated with the conditioned medium for $24 \mathrm{~h}$, when they were trypsinized, counted and re-plated. The adherent cells were estimated by using Crystal Violet assay up to 1.5 or $3.0 \mathrm{~h}$ of seeding. The control group was considered by maintaining the cells with the classical cell medium.

\section{Results and discussion}

The chemical composition of the samples is displayed in Table 1. Chemical mappings of the samples are exhibited in Fig. 1. A comparison between theoretical density values and the samples' density values is shown in Fig. 2. The average composition was close to the proposed stoichiometric values, and metallic impurities were not present in significant amounts. The compositional deviation remained within the range of allowable values, as specified for ASTM standards of some commercial alloys used in biomedical field [27]. The concentration of oxygen and nitrogen gases (not shown) remained around $1000 \mathrm{ppm}$ and $50 \mathrm{ppm}$, respectively. All samples displayed homogeneous distribution of the alloying elements, which confirms the high quality of the prepared samples. The experimental values of the density were near to those expected,

Table 1

Chemical composition of Ti-15Zr-Mo alloys by EDS.

\begin{tabular}{llll}
\hline Alloys & Ti (wt\%) & Zr (wt\%) & Mo (wt\%) \\
\hline Ti-15Zr & $84.8 \pm 0.7$ & $15.2 \pm 0.7$ & - \\
Ti-15Zr-2.5Mo & $81 \pm 1$ & $16.2 \pm 0.9$ & $3 \pm 1$ \\
Ti-15Zr-5Mo & $79 \pm 1$ & $15.0 \pm 0.9$ & $5.7 \pm 0.9$ \\
Ti-15Zr-7.5Mo & $77 \pm 1$ & $14 \pm 1$ & $8 \pm 1$ \\
Ti-15Zr-10Mo & $73 \pm 1$ & $16 \pm 1$ & $11 \pm 1$ \\
Ti-15Zr-12.5Mo & $72.5 \pm 0.5$ & $14.4 \pm 0.4$ & $13.0 \pm 0.5$ \\
Ti-15Zr-15Mo & $69 \pm 1$ & $16.0 \pm 0.8$ & $15 \pm 1$ \\
Ti-15Zr-20Mo & $63.7 \pm 0.9$ & $16.1 \pm 0.7$ & $20.2 \pm 0.8$ \\
\hline
\end{tabular}




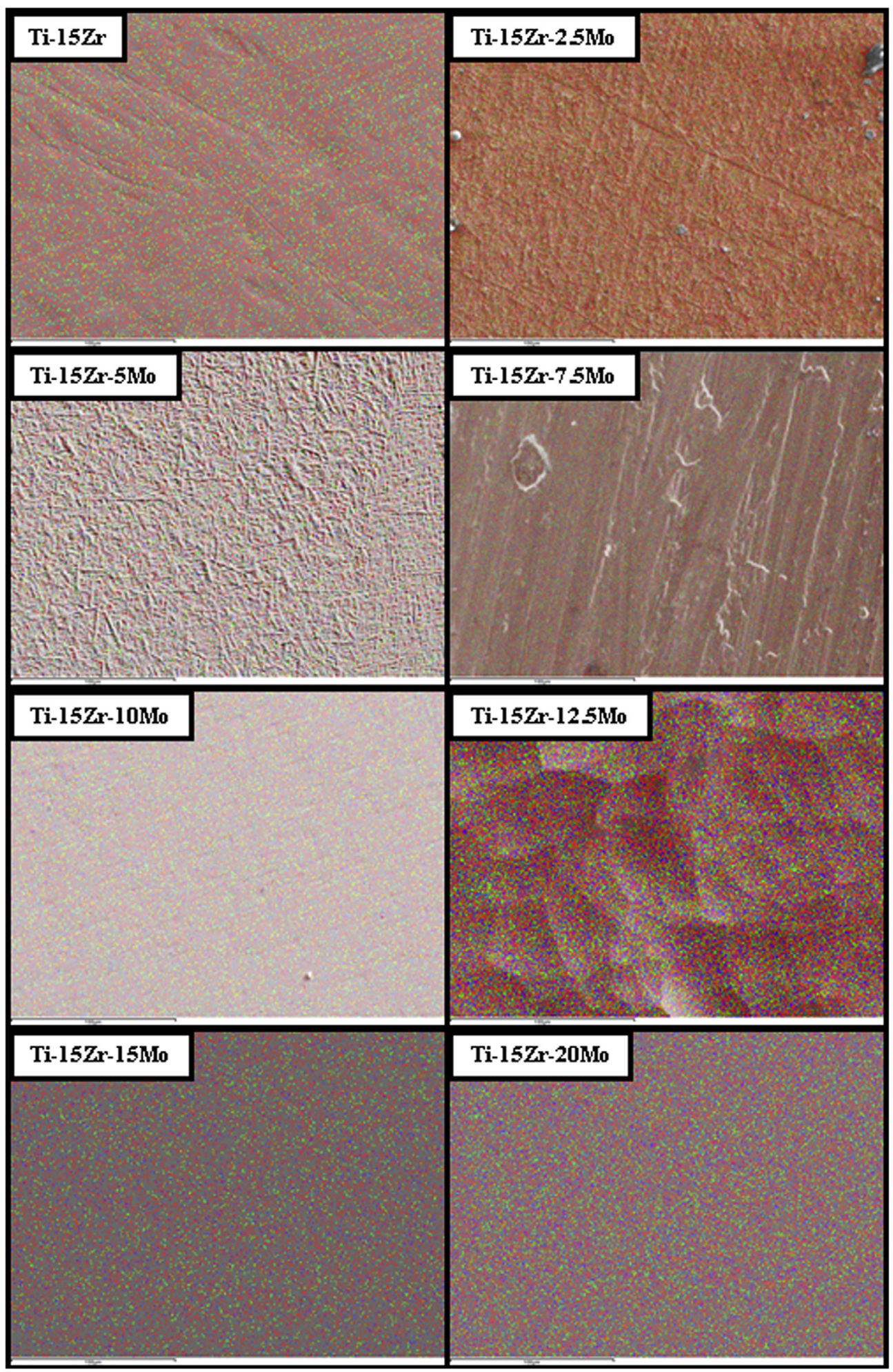

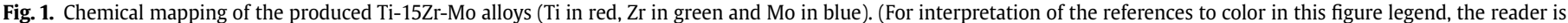
referred to the Web version of this article.)

indicating an approximation to the nominal stoichiometry. The small deviation between density theoretical and experimental values was a result of the eventual metallic (e.g. Al, $\mathrm{Cr}, \mathrm{Fe}, \mathrm{Mn}$ and $\mathrm{Ni}$ ) and interstitial (e.g. $\mathrm{O}, \mathrm{C}, \mathrm{N}$ and $\mathrm{H}$ ) impurities from the raw materials. The increasing density values were caused by the higher densities of zirconium $\left(6.51 \mathrm{~g} / \mathrm{cm}^{3}\right)$ and molybdenum $\left(10.22 \mathrm{~g} / \mathrm{cm}^{3}\right)$ relative to the density of titanium $\left(4.51 \mathrm{~g} / \mathrm{cm}^{3}\right)$ [28]. Density is an important physical property to evaluate in biomedical materials, once the specific strength (mechanical strength to density ratio) is one of the requirements for the mechanical biocompatibility [27].

The samples' XRD patterns (Fig. 3) demonstrate that the crystalline structure was clearly dependent on the alloying elements. 


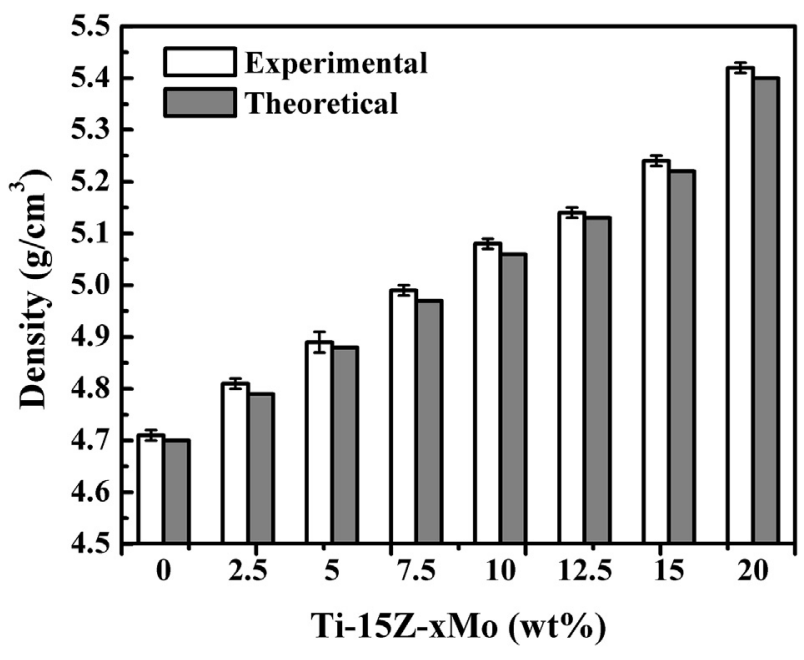

Fig. 2. Density values for Ti-15Zr-Mo alloys.

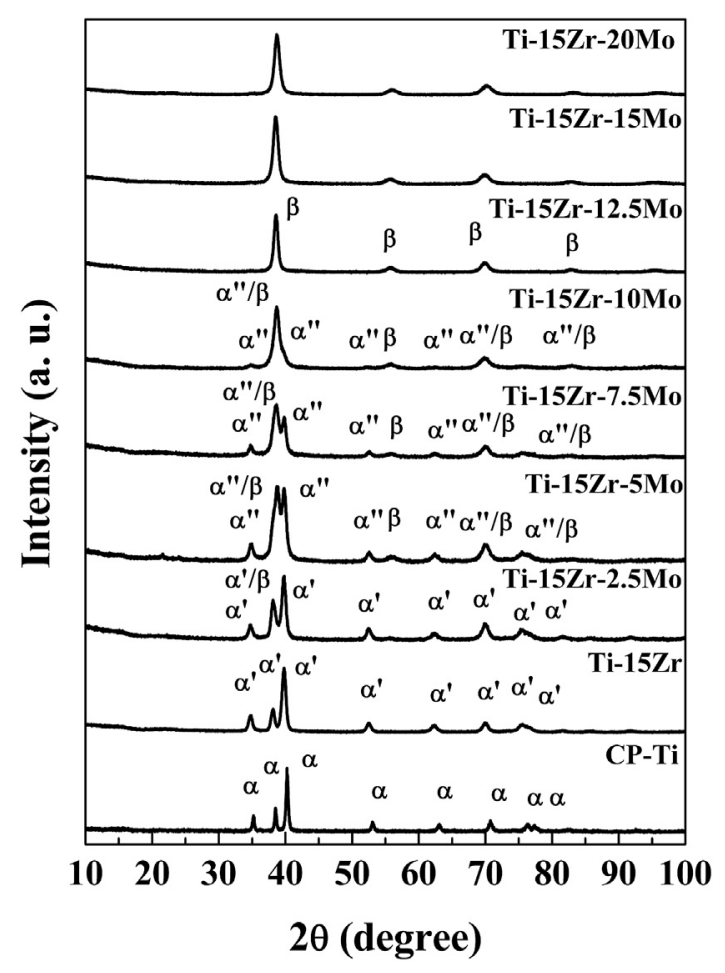

Fig. 3. XRD patterns for Ti-15Zr-Mo alloys, in comparison with CP-Ti.

Ti-15Zr alloy exhibited the same $\alpha$-type pattern as CP-Ti, but the peaks were slightly shifted toward low $\theta$ values because of

Table 2

Rietveld's parameters for Ti-15Zr-Mo alloys.

\begin{tabular}{lllll}
\hline Alloy & GoF & $\mathrm{RF}^{2}(\%)$ & $\mathrm{Rwp}(\%)$ & $\mathrm{Rp}(\%)$ \\
\hline Ti-15Zr & 1.808 & 4.46 & 7.57 & 5.85 \\
Ti-15Zr-2.5Mo & 2.237 & 6.10 & 8.55 & 6.54 \\
Ti-15Zr-5Mo & 1.501 & 9.46 & 6.47 & 5.03 \\
Ti-15Zr-7.5Mo & 1.368 & 6.99 & 6.96 & 5.40 \\
Ti-15Zr-10Mo & 1.491 & 4.64 & 7.74 & 5.97 \\
Ti-15Zr-12.5Mo & 1.418 & 6.46 & 6.76 & 5.27 \\
Ti-15Zr-15Mo & 1.554 & 3.57 & 6.57 & 5.02 \\
Ti-15Zr-20Mo & 1.660 & 9.03 & 9.89 & 7.81 \\
\hline
\end{tabular}

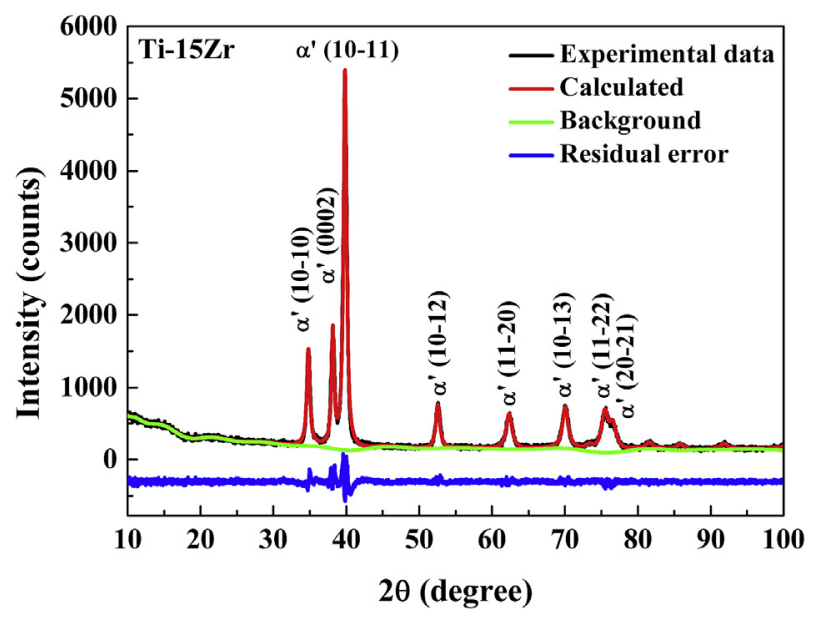

Fig. 4. Refined diffractogram for Ti-15Zr alloy.

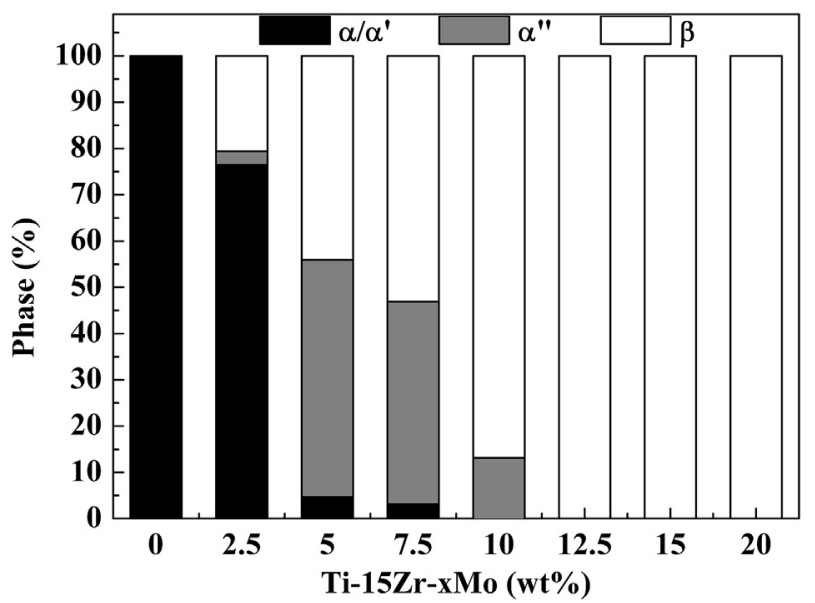

Fig. 5. Quantitative phase analysis for Ti-15Zr-Mo alloys.

distortion to the hcp structure caused by the zirconium addition, suggesting the formation of $\alpha^{\prime}$ phase (distorted hcp structure) [29]. The phase composition changed in accordance with the amount of molybdenum in the solid solution, and the $\alpha^{\prime}, \alpha^{\prime \prime}$, and $\beta$ phases coexisted between Ti-15Zr-2.5Mo and Ti-15Zr-10Mo. Ti-15Zr12.5 Mo only exhibited peaks of $\beta$ phase, and the addition of molybdenum resulted in a shift toward higher $\theta$ values. The distortion of the hcp and bcc structures was produced by the atomic radii of molybdenum $(0.136 \mathrm{~nm})$ and zirconium $(0.159 \mathrm{~nm})$, which are distinct from titanium $(0.145 \mathrm{~nm})$ and can cause changes to cell

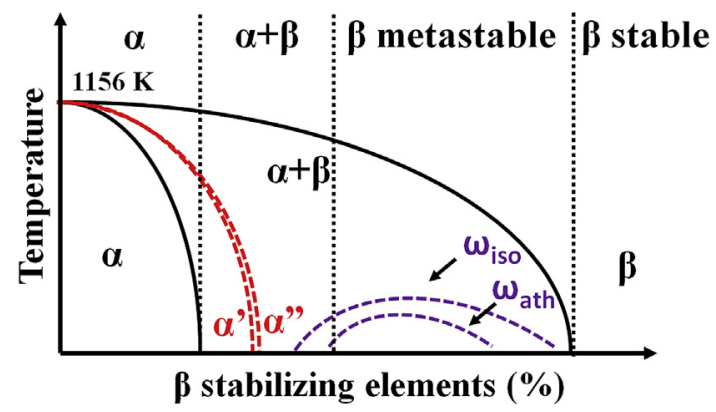

Fig. 6. Pseudo-binary phase diagram of Ti alloys. 
parameters [21, 28]. Ho et al. [30] studied the $\beta$-stabilizer effect of molybdenum in a solid solution with titanium, finding only the $\alpha^{\prime}$ phase in the Ti-5Mo alloy as well as a coexistence of $\alpha^{\prime}, \alpha^{\prime \prime}$ and $\beta$ phases in compositions up to Ti-9Mo. Above Ti-10Mo, only the $\beta$ phase was observed in the as-cast alloys. In another study, Ho et al. [31] observed structural changes to the Ti-10Zr alloy with the addition of molybdenum in as-cast condition. The Ti-10Zr alloy exhibited only $\alpha^{\prime}$ phase, which changed to $\alpha$ " phase in Ti-10Zr-5Mo. From Ti-10Zr-7.5Mo, only a metastable $\beta$ phase with a small quantity of $\omega$ phase was observed. Kuroda et al. [32] studied the crystalline structure of as-cast Ti-20Zr-xMo $(x=0,2.5,5,7.5$, and $10 \mathrm{wt} \%$ ) alloys, finding a full $\beta$ phase formation in the Ti-20Zr-10Mo alloy. The obtained XRD results support previous studies' assumptions about the supplementary $\beta$-stabilization effect of zirconium when combined in a solid solution with molybdenum.

Rietveld's refinement was used to analyze the phase compositions in the XRD patterns. The refinement parameters are depicted in Table 2. A visual plot of the refinements can be sawn in Fig. 4 and

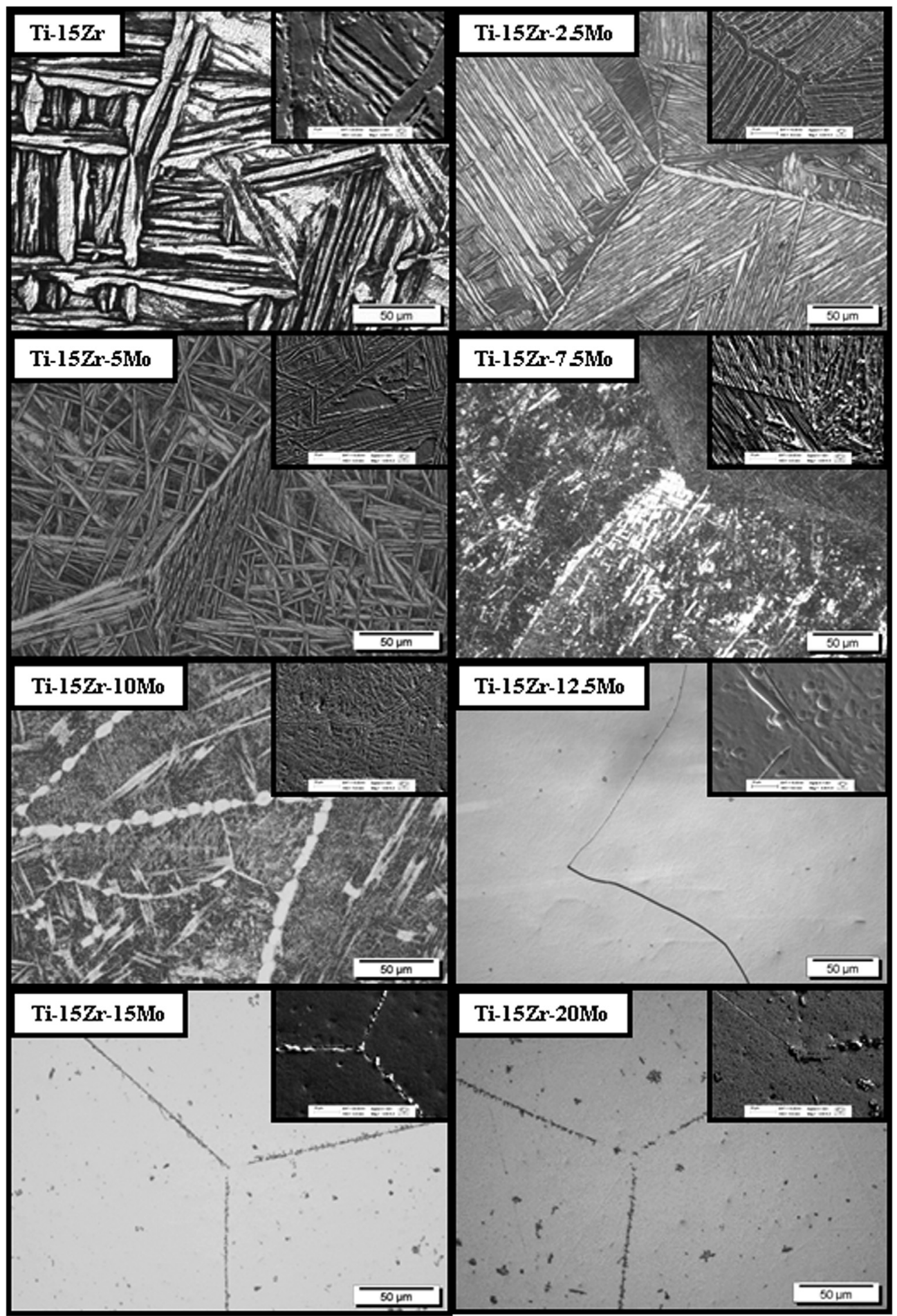

Fig. 7. OM (onset) and SEM (inset) images for Ti-15Zr-Mo alloys. 


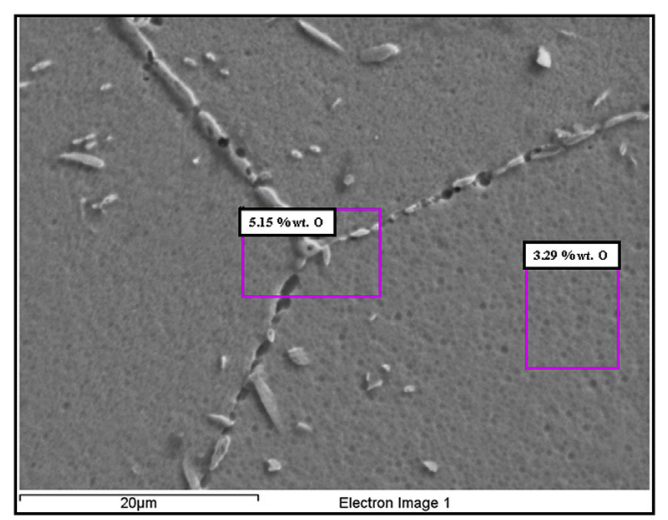

Fig. 8. EDS analysis of the grain boundary region in the Ti-15Zr-15Mo alloy.

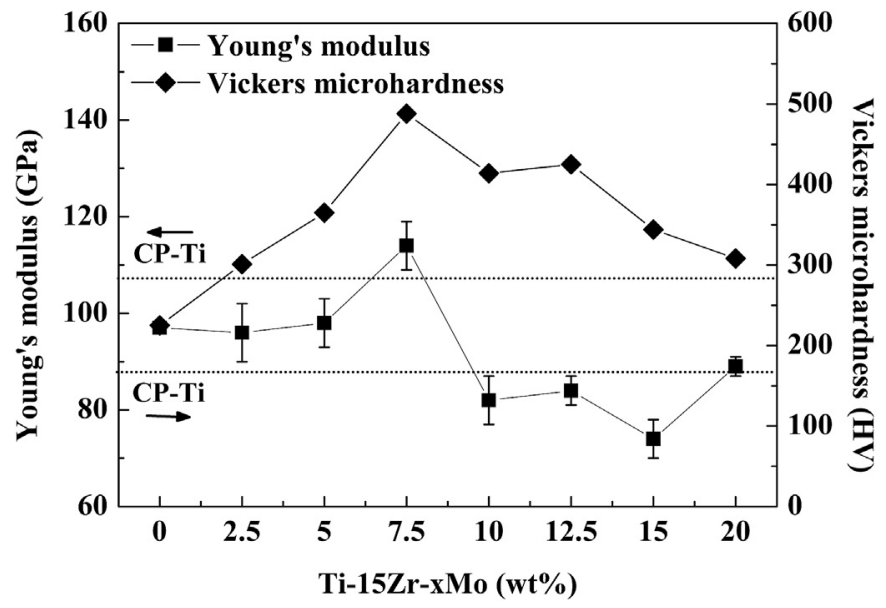

Fig. 9. Selected mechanical properties for Ti-15Zr-Mo alloys.

the phase composition results are presented in Fig. 5. The goodness of fit and R's of the Rietveld's analysis parameters remained relatively low and close to those observed in previous studies [33, 34]. A visual plot of the refinements (Fig. 4) showed that experimental and simulated patterns closely aligned. It indicates that the refinements were conducted successfully, overcoming any effects of crystallographic texture and peaks' convolution of the samples.

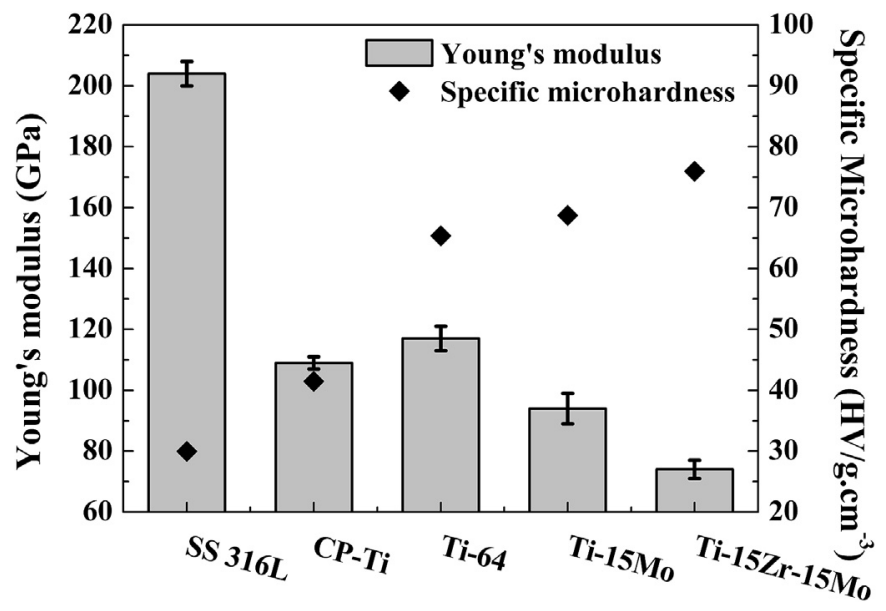

Fig. 10. Comparison of selected mechanical properties of some metallic biomaterials.

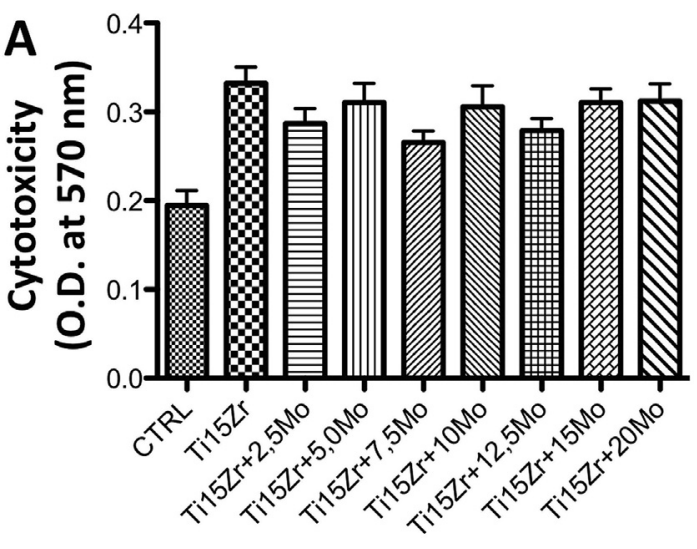

Fig. 11. Cytotoxic test results for Ti-15Zr-Mo alloys.

Phase composition results (Fig. 5), obtained from the Rietveld's refinements, confirmed the changing proportions of $\alpha^{\prime}, \alpha$, and $\beta$ phases in accordance with the amount of molybdenum present. Ti$15 \mathrm{Zr}-10 \mathrm{Mo}$ was formed mainly by the $\beta$ phase (85\%). A gradual suppression of martensitic phases ( $\alpha^{\prime}$ and $\left.\alpha^{\prime \prime}\right)$ was observed as the amount of molybdenum changed, indicating a clear $\beta$ phase stabilization. The global phase composition of the alloys as function of Mo content seemed very close to that presented in pseudo-binary isomorphous diagrams of Ti alloys, as illustrated in Fig. 6. As it is well known, pseudo-binary diagrams are an indicative of Ti phase composition as function of $\beta$-stabilizers elements, exhibiting the range of $\alpha, \alpha+\beta$ and $\beta$ regions, and also the specific compositions where metastable phases might take place (e.g. martensitic $\alpha^{\prime} / \alpha^{\prime \prime}$ and $\omega$ phases) [35, 36]. Our result confirms a combined effect of $\mathrm{Zr}$ and Mo elements on $\beta$ phase stabilization. Regarding the lattice parameters, the enveloped $\mathrm{Ti}$ phase peaks around $40^{\circ}$ limited an exact determination by the Rietveld's method. Once the cell parameters could be affected by the phase composition (e.g. microstrains between the phase boundaries), thus these values could not be reliable [37].

The microstructural evolution of Ti-15Zr as the amount of molybdenum is depicted in Fig. 7. An EDS analysis of the samples is presented in Fig. 8. The amount of molybdenum acted in the $\beta$ stabilization and decreased the Ms temperature [21, 35]. The Ti$15 \mathrm{Zr}$ alloy exhibited only the laths of $\alpha^{\prime}$ phase, while the grain boundaries of the $\beta$ phase and the needles of $\alpha$ " phase were clearly visible when molybdenum concentration measured is below $10 \mathrm{wt}$ \%. In special for the Ti-15Zr-10Mo alloy (Fig. 7), it is possible to observe $\alpha^{\prime} / \alpha^{\prime \prime}$ phase (white) together the $\beta$ phase matrix (dark). From the Ti-15Zr-12.5Mo alloy, only equiaxed grains of the $\beta$ phase of an average size larger than $500 \mu \mathrm{m}$ are present, indicating that the $\beta$ phase was fully stabilized by the amount of alloying elements. Dark spots observed along the $\beta$ phase grains in the Ti-15Zr-15Mo and Ti-15Zr-20Mo alloys was a result of pitting corrosion during metallographic preparation. Small precipitates of $\alpha$ phase are visible along grain boundaries in SEM images of the Ti-15Zr-15Mo and Ti-15Zr-20Mo alloys, which are possibly caused by the agglomeration of interstitial $\alpha$-stabilizer elements (mainly oxygen) during thermomechanical processing, once $\mathrm{O}$ atoms have a sharp impact on the $\alpha$-stabilization, being much higher than $\mathrm{Zr}$. It is clearly denoted in the Al-equivalent description $\left([\mathrm{Al}]_{\mathrm{eq}}=[\mathrm{Al}]+1 / 6\right.$ $[\mathrm{Zr}]+1 / 3[\mathrm{Sn}]+10[0]$, elements expressed in at\%), which is used to predict phase composition of Ti alloys [35]. As these agglomerates are in low quantity on the microstructure, they can be difficult to detect by XRD measurements. This assumption was confirmed by EDS analysis of the samples (Fig. 8). 
Selected mechanical properties of the Ti-15Zr-based alloys are displayed in Fig. 9. Statistical analysis $(p<0.01)$ indicated that the obtained values were significantly different from each other. Vickers microhardness values were higher than those observed in CP-Ti $(187 \pm 4 \mathrm{HV})$ as a result of solid solution strengthening by the alloying elements [21]. However, the non-linear increase of the micro-hardness with the composition suggests that phase precipitation strengthening, in special by metastable phases, is also occurring in the alloys [29, 38]. Ti-15Zr-7.5Mo alloy presented the highest micro-hardness value ( $488 \pm 4 \mathrm{HV}$ ) due to the mixture of $\omega$, $\alpha$ " and $\beta$ phases, which blocked plastic deformation and prevented the slip sliding of the atomic planes [21]. The metastable $\omega$ phase on Ti-15Zr-7.5Mo alloy was confirmed by TEM analysis in an earlier study [39]. The posterior micro-hardness decay in Mo-richer samples confirms the suppression of this phase by the alloying elements. As it is well-known, $\mathrm{Zr}$ has a significant action on blocking $(110)_{\beta}$ plane collapses, which is crucial for $\omega$ phase nucleation [22, 40].

Young's modulus values showed a gradual decrease with the increase of molybdenum content (Fig. 9). With the exception of Ti15Zr-7.5Mo, all alloys maintained values lower than those of CP-Ti (108 $\pm 3 \mathrm{GPa}$ ) due to the presence of $\alpha$ " and $\beta$ phases, which have lower values than the $\alpha$ phase [21, 41]. The Ti-15Zr-7.5Mo alloy presented the highest Young's modulus value (114 $\pm 5 \mathrm{GPa})$ due to the expected effect of $\omega$ phase precipitation [41]. Ti-15Zr-20Mo alloy exhibited a remarkable increase to its Young's modulus due

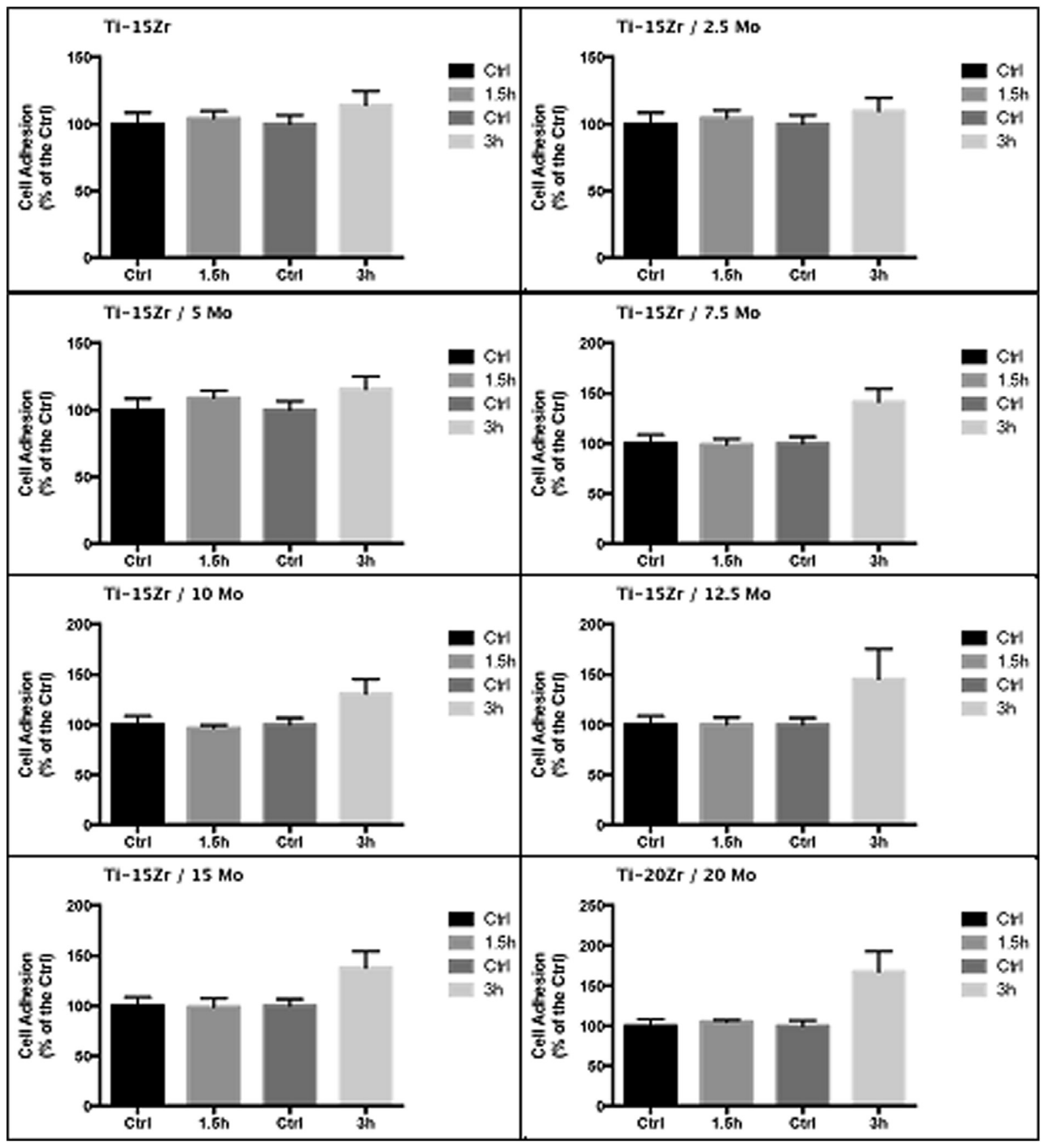

Fig. 12. Ti-15Zr-Mo alloys effect on pre-osteoblast adhesion. 
to the change of bound energy in the bcc structure provided by the high amount of molybdenum. The dependence of Young's modulus with alloy's composition in Ti alloys has been extensively studied, once these kind of materials show diverse industrial applications. Experimental and theoretical studies have demonstrated that after $\beta$ phase stabilization, the addition of some $\beta$-stabilizers elements (such as $\mathrm{Mo}, \mathrm{Nb}$ and $\mathrm{Ta}$ ) increase the Young's modulus. It was found that it occurs due to the increase of bound energy between the alloying elements and $\mathrm{Ti}$ atoms on the metallic matrix. As a result, there is an attenuation of atomic diffusion and dislocations movements, which favors an increase of Young's modulus [35, 42].

A comparison of specific microhardness (the ratio of microhardness to density) and Young's modulus values between Ti-15Zr$15 \mathrm{Mo}$ and various other metallic materials is presented in Fig. 10. It is compared the values between Ti-15Zr-15Mo and SS 316L [43], $\alpha$ type CP-Ti (grade 2) [44], $\alpha+\beta$-type Ti-6Al-4V [45], and $\beta$-type Ti$15 \mathrm{Mo}$ [27] alloys, were made. All materials were measured in the same experimental apparatus. The specific microhardness was the highest $(p<0.01)$ in the Ti-15Zr-15Mo alloy $\left(73 \pm 3 \mathrm{HV} / \mathrm{g} \cdot \mathrm{cm}^{-3}\right)$, which indicates better resistance to plastic deformation by biomechanical loads. Conversely, its Young's modulus value ( $85 \mathrm{GPa}$ ) was the lowest $(p<0.01)$, which is optimal for preventing stress shielding. Therefore, this alloy has excellent mechanical compatibility for use in biomedical implants. However, tensile and fatigue tests are still required to deeply assess the alloy's potential for use in load-bearing implants.

The alloys' cytotoxicity test results are displayed in Fig. 11. The pre-osteoblast adhesion on the studied alloys is showed in Fig. 12. There were no significantly detectable differences in the samples' absorbance levels in relation to the amount of molybdenum in each studied condition. All samples presented values close to the negative control, which indicated that all of the alloying elements had a low level of cytotoxicity [26]. The preliminarily results indicated that the samples exhibit a tolerable level of cytotoxicity, but further analysis would provide additional information on cell adhesion, proliferation, and differentiation when in contact with the studied alloys. Moreover, it was very interesting to observe a positive effect of the molybdenum-containing Ti-15Zr-based alloys on preosteoblast adhesion, since potential metal alloys for being applied as bone implantable devices require biological properties able to stimulate pre-osteoblast cells growth surrounding, favoring the new bone deposition during a well-known osteointegration process.

\section{Conclusion}

The structure, microstructure, selected mechanical properties, and biological effects of Ti-15Zr-xMo alloys were studied to establish these materials' potential for use in biomedical applications. From the results presented in this paper, we conclude:

- Phase composition and microstructure were sensible to the alloying elements (zirconium and molybdenum), and both elements played a role in $\beta$ phase stabilization.

- The Vickers micro-hardness test showed high values due to solid solution and phase precipitation strengthening.

- Young's modulus values decreased due to $\beta$ phase stabilization.

- The Ti-15Zr-7.5Mo alloy presented the highest mechanical properties values due to $\omega$ phase precipitation.

- The cytotoxicity test indicated that the studied alloys presented tolerable cytotoxicity levels when in contact with cells.

- The studied alloys promoted an increase on pre-osteoblast adhesion.

- The Ti-15Zr-15Mo alloy presented the best combination of properties for use in biomedical applications.

\section{Acknowledgements}

The authors thank the Physics Department at UNESP's School of Sciences for providing access to its XRD and SEM equipment. This study was funded in part by FAPESP (grants \#2010/20440-7; \#2012/22742-6; \#2014/06.221-1; \#2014/22689-3 and \#2015/ 00851-6) and CNPq (grants \#481.313/2012-5 and \#307.279/2013$8)$.

\section{References}

[1] M. Niinomi, M. Nakai, J. Hieda, Development of new metallic alloys for biomedical applications, Acta Biomater. 8 (2012) 3888-3903.

[2] M. Geetha, A.K. Singh, R. Asokamani, A.K. Gogia, Ti based biomaterials, the ultimate choice for orthopaedic implants - a review, Prog. Mater. Sci. 54 (2009) 397-425.

[3] B.D. Ratner, A.S. Hoffman, F.J. Schoen, J.E. Lemons, Biomaterials Science: an Introduction to Materials in Medicine, Academic Press, San Diego (CA), USA, 1996.

[4] M. Niinomi, M. Nakai, Titanium-based biomaterials for preventing stress shielding between implant devices and bone, Int. J. Biomater. 2011 (2011), 836587.

[5] H.J. Rack, J.I. Qazi, Titanium alloys for biomedical applications, Mater. Sci. Eng. C 26 (2006) 1269-1277.

[6] T.A.G. Donato, L.H. de Almeida, R.A. Nogueira, T.C. Niemeyer, C.R. Grandini, R. Caram, S.G. Schneider, A.R. Santos, Cytotoxicity study of some Ti alloys used as biomaterial, Mater. Sci. Eng. C 29 (2009) 1365-1369.

[7] M. Niinomi, Recent research and development in titanium alloys for biomedical applications and healthcare goods, Sci. Technol. Adv. Mater. 4 (2003) 445-454.

[8] M. Niinomi, Metallic biomaterials, J. Artif. Organs Offic. J. Jpn Soc. Artif. Organs 11 (2008) 105-110.

[9] M. Niinomi, Y. Liu, M. Nakai, H. Liu, H. Li, Biomedical titanium alloys with Young's moduli close to that of cortical bone, Regen. Biomater. (2016) rbw016.

[10] W.-F. Ho, C.-H. Cheng, C.-H. Pan, S.-C. Wu, H.-C. Hsu, Structure, mechanical properties and grindability of dental Ti-10Zr-X alloys, Mater. Sci. Eng. C 29 (2009) 36-43.

[11] C.-H. Cheng, H.-C. Hsu, S.-C. Wu, H.-W. Wang, W.-F. Ho, Effects of chromium addition on structure and mechanical properties of Ti-10Zr alloy, J. Alloy Comp. 484 (2009) 524-528.

[12] M. Niinomi, T. Akahori, T. Takeuchi, S. Katsura, H. Fukui, H. Toda, Mechanica properties and cyto-toxicity of new beta type titanium alloy with low melting points for dental applications, Mater. Sci. Eng. C 25 (2005) 417-425.

[13] S. Samuel, S. Nag, T.W. Scharf, R. Banerjee, Wear resistance of laser-deposited boride reinforced $\mathrm{Ti}-\mathrm{Nb}-\mathrm{Zr}-\mathrm{Ta}$ alloy composites for orthopedic implants, Mater. Sci. Eng. C 28 (2008) 414-420.

[14] H.-C. Hsu, S.-C. Wu, Y.-C. Sung, W.-F. Ho, The structure and mechanical properties of as-cast Zr-Ti alloys, J. Alloy Comp. 488 (2009) 279-283.

[15] J.R.S. Martins Júnior, R.A. Nogueira, R.O.d. Araújo, T.A.G. Donato, V.E. AranaChavez, A.P.R.A. Claro, J.C.S. Moraes, M.A.R. Buzalaf, C.R. Grandini, Preparation and characterization of Ti-15Mo alloy used as biomaterial, Mater. Res. 14 (2011) 107-112.

[16] Y.-y. Chen, L.-j. Xu, Z.-g. Liu, F.-t. Kong, Z.-y. Chen, Microstructures and properties of titanium alloys Ti-Mo for dental use, Trans. Nonferrous Metals Soc. China 16 (2006) s824-s828.

[17] P. Fernandes Santos, M. Niinomi, H. Liu, K. Cho, M. Nakai, A. Trenggono S. Champagne, H. Hermawan, T. Narushima, Improvement of microstructure, mechanical and corrosion properties of biomedical Ti-Mn alloys by Mo addition, Mater. Des. 110 (2016) 414-424.

[18] Y. Abd-elrhman, M.A.H. Gepreel, A. Abdel-Moniem, S. Kobayashi, Compatibility assessment of new V-free low-cost Ti-4.7Mo-4.5Fe alloy for some biomedical applications, Mater. Des. 97 (2016) 445-453.

[19] S. Ozan, J. Lin, Y. Li, R. Ipek, C. Wen, Development of Ti-Nb-Zr alloys with high elastic admissible strain for temporary orthopedic devices, Acta Biomater. 20 (2015) 176-187.

[20] M.G. de Mello, C.F. Salvador, A. Cremasco, R. Caram, The effect of Sn addition on phase stability and phase evolution during aging heat treatment in $\mathrm{Ti}-\mathrm{Mo}$ alloys employed as biomaterials, Mater. Char. 110 (2015) 5-13.

[21] D.R.N. Correa, P.A.B. Kuroda, C.R. Grandini, Structure, microstructure, and selected mechanical properties of Ti-Zr-Mo alloys for biomedical applications, Adv. Mater. Res. 922 (2014) 75-80.

[22] X. Zhao, M. Niinomi, M. Nakai, T. Ishimoto, T. Nakano, Development of high Zr-containing Ti-based alloys with low Young's modulus for use in removable implants, Mater. Sci. Eng. C 31 (2011) 1436-1444.

[23] D.R.N. Correa, F.B. Vicente, T.A.G. Donato, V.E. Arana-Chavez, M.A.R. Buzalaf, C.R. Grandini, The effect of the solute on the structure, selected mechanical properties, and biocompatibility of Ti-Zr system alloys for dental applications Mater. Sci. Eng. C-Mater. Biol. Appl. 34 (2014) 354-359.

[24] E384-11e1, in: Standard Test Method for Knoop and Vickers Hardness of Materials, ASTM International, West Conshohocken, PA, 2011.

[25] E1876-09, in: Standard Test Method for Dynamic Young's Modulus, Shear 
Modulus, and Poisson's Ratio by Impulse Excitation of Vibration, ASTM International, West Conshohocken, PA, 2009.

[26] ISO, in: Biological Evaluation of Medical Devices - Part 5: Tests for in Vitro Cytotoxicity, 10993-5, International Organization for Standardization, Geneve, Switzerland, 2009.

[27] F2066-08, in: Standard Specification for Wrought Titanium-15Molybdenium alloy for Surgical Implant Applications (UNS R58150), ASTM International, West Conshohocken, PA, 2008.

[28] D.R.N. Correa, F.B. Vicente, R.O. Araújo, M.L. Lourenç, P.A.B. Kuroda, M.A.R. Buzalaf, C.R. Grandini, Effect of the substitutional elements on the microstructure of the Ti-15Mo-Zr and Ti-15Zr-Mo systems alloys, J. Mater. Res. Technol. 4 (2015) 180-185.

[29] D.R. Correa, F.B. Vicente, T.A. Donato, V.E. Arana-Chavez, M.A. Buzalaf, C.R. Grandini, The effect of the solute on the structure, selected mechanical properties, and biocompatibility of Ti-Zr system alloys for dental applications Mater. Sci. Eng. C, Mater. Biol. Appl. 34 (2014) 354-359.

[30] W.F. Ho, C.P. Ju, J.H. Chern Lin, Structure and properties of cast binary Ti-Mo alloys, Biomaterials 20 (1999) 2115-2122.

[31] W.-F. Ho, S.-C. Wu, S.-K. Hsu, Y.-C. Li, H.-C. Hsu, Effects of molybdenum content on the structure and mechanical properties of as-cast Ti-10Zr-based alloys for biomedical applications, Mater. Sci. Eng. C 32 (2012) 517-522.

[32] P.A. Kuroda, M.A. Buzalaf, C.R. Grandini, Effect of molybdenum on structure microstructure and mechanical properties of biomedical Ti-20Zr-Mo alloys, Mater. Sci. Eng. C, Mater. Biol. Appl. 67 (2016) 511-515.

[33] J.R. Severino Martins, C.R. Grandini, Structural characterization of Ti-15Mo alloy used as biomaterial by Rietveld method, J. Appl. Phys. 111 (2012), 083535.

[34] S. Banumathy, R.K. Mandal, A.K. Singh, Structure of orthorhombic martensitic phase in binary Ti-Nb alloys, Journal of Appl. Phys. 106 (2009), 093518.

[35] D. Banerjee, J.C. Williams, Perspectives on titanium science and technology,
Acta Mater. 61 (2013) 844-879.

[36] Y. Li, C. Yang, H. Zhao, S. Qu, X. Li, Y. Li, New developments of Ti-Based alloys for biomedical applications, Materials 7 (2014) 1709-1800.

[37] N.V.Y. Scarlett, I.C. Madsen, Quantification of phases with partial or no known crystal structures, Powder Diffr. 21 (2012) 278-284.

[38] X. Zhao, M. Niinomi, M. Nakai, J. Hieda, Beta type Ti-Mo alloys with changeable Young's modulus for spinal fixation applications, Acta Biomater. 8 (2012) 1990-1997.

[39] D.R.N. Correa, P.A.B. Kuroda, C.R. Grandini, L.A. Rocha, F.G.M. Oliveira, A.C. Alves, F. Toptan, Tribocorrosion behavior of $\beta$-type Ti-15Zr-based alloys, Mater. Lett. 179 (2016) 118-121.

[40] C.D. Yang, S.P. Wang, J.J. Shi, C.H. Wang, Z.M. Ren, G.H. Cao, Microstructures and mechanical properties of as-cast titanium-zirconium-molybdenum ternary alloys, Mater. Werkst. 49 (2018) 30-38.

[41] E. Sukedai, M. Shimoda, H. Nishizawa, Y. Nako, Nucleation behaviour of $\beta$ to $\omega$ phase transformations in $\beta$-type Ti-Mo alloys, Mater. Trans. 52 (2011) 324-330.

[42] D. Raabe, B. Sander, M. Friák, D. Ma, J. Neugebauer, Theory-guided bottom-up design of $\beta$-titanium alloys as biomaterials based on first principles calculations: theory and experiments, Acta Mater. 55 (2007) 4475-4487.

[43] F138-13a, in: Standard Specification for Wrought 18Chromium-14Nickel2.5Molybdenum Stainless Steel Bar and Wire for Surgical Implants (UNS S31673), ASTM International, West Conshohocken, PA, 2013.

[44] F67-06, in: Standard Specification for Unalloyed Titanium, for Surgical Implant Applications (UNS R50250, UNS R50400, UNS R50550, UNS R50700), ASTM International, West Conshohocken, PA, 2006.

[45] F1108-04, in: Standard Specification for Titanium-6aluminum-4vanadium alloy Castings for Surgical Implants (UNS R56406), ASTM International, West Conshohocken, PA, 2004. 